\title{
OCURRENCIA Y PROPIEDADES DE Xanthomonas campestris pv. phaseoli Y XANTHOMONAS PECTOLÍTICAS, EPIFÍTICAS EN MALEZAS1
}

\author{
Rosendo Angeles $^{2}$, Anne K. Vidaver $^{3}$
}

\section{COMPENDIO 4}

La poblaciones de Xanthomonas campestris pv.phaseoli y otras Xanthomonas atípicas ocurren en forma natural en malezas asintomáticas. Se examinaron 77 muestras de 21 especies de malezas dentro de campos infectados de Tizón común en San Juan, Higuey, Constanza de la República Dominicana. Los aislamientos fueron realizados añadiéndoles $10 \mathrm{ml}$ de bufer $\left(12,5 \mathrm{mM} \mathrm{K}_{2} \mathrm{PO}+10 \mathrm{mM}\right.$ $\mathrm{MgSO} 4, \mathrm{pH}<7,1)$. Las pruebas de patogenicidad se realizaron en la variedad de frijol Dark Red Kidney, inoculando a plantas, hojas trifoliadas y legumbres. Para confirmar la reacción de hidrólisis de almidón con metil violeta y metil verde, evaluándose la producción de pigmento marrón y cromatografía de capa fina del pigmento Xanthomonadin. De los resultados observados, se encontraron 14 muestras en 8 especies de malezas para $X$. campestris pv. phaseoli y 23 especies de malezas para Xanthomonas atípicas.Los aislamientos patogénicos de inoculaciones en hojas a las 2 semanas, la zona amarilla se había expandido y cubría un área amplia alrededor del centro necrótico marrón. Las legumbres de frijol Inoculadas con aislamientos patogénicos mostraron los síntomas típicos alrededor de los 10 días. Todos los aislamientos patogénicos en las hojas fueron patogénicos en el fruto. Ninguno de los aislamientos de malezas colectados después de la cosecha en la zona de Constanza causó síntomas en hojas de frijol. Las muestras de malezas colectadas dentro de campos infectados de Tizón común, tenían más aislamientos patogénicos de $X$. campestris pv. phaseoli que las muestras que provenían del exterior de los campos o después de la cosecha. El hallazgo de 8 especies de malezas pertenecientes a 6 familias botánicas, las cuales pueden actuar como hospederos sin síntomas, indica que otras especies podrían ser encontradas albergando $X$. campestris pv. phaseoli epifitas.

Palabras clave adicionales: Bacterias, frijol, patógenos, tizón común.

\section{INTRODUCCION}

Numerosos microorganismos patógenos de plantas tienen la capacidad de crecer en la superficie de plantas sanas sin causar síntomas visibles (Leben, 1965). Varias especies de bacteriosis fitopatógenas tienen una fase epifítica en sus hospederos u otras plantas, donde se multiplican y son la fuente de inóculo más probables para iniciar la enfermedad en los cultivos (Hirano, 1983; Schuster y Coyne, 1974). Algunas bacterias pueden colonizar el frijol (Phaseolus vulgaris ) y multiplicarse en forma epifítica en las hojas, antes de producirse brotes de enfermedades (Morris y Rouse, 1982).

\begin{abstract}
Populations of Xanthomonas campestris pv. phaseoli and other Xanthomonas occur in natural form la non symptomatic weeds. Sevently seven samples of twenty one weed species from fields Infested with common blight "Tizón común" In San Juan, Higuey, Constanza of the Dominkan Republic were evaluated. The isolations were obtained by adding $10 \mathrm{ml}$ of the buffer $(12.5 \mathrm{mM} \mathrm{K} 2 \mathrm{PO} 4+10$ $\mathrm{mM} \mathrm{Mg} \mathrm{SO} 4, \mathrm{ph}<7.1$ ). The pathogenicity tests were performed on the Dark Red Kidney bean, by inoculating plants, trifoliates and seed pods. To confirm the starch hydrolisis reaction with methyl violet and methyl green, an evaluation of the production of brown dye and thin layer chromatography for the Xanthomonadin pigment was made. Of the observed results, fourteen samples and eight species of weeds of $X$. campestris pv. phaseoli and 23 species of weeds of atypical Xanthomonas were found. The pathogenic isolations from leaf innoculum at two weeks the yellow zone had expanded and covered a wide area around the necrotic brown center. The bean seed pods inoculated with pathogenic isolates showed typical symptoms around ten days. All the pathogenic isolates on the leaves became pathogenic on the seed pods. None of the isolates of collected weeds after harvest. In the "Constanza" area showed any symptoms on the bean leaves. The weed samples collected from the common blight Infested fields had more pathogenic of isolates $X$. campestris pv. phaseoli than the samples taken from the outside ends of the fields or after harvest. We found eight weed species all belonging to six botanic families which might act as sympto-matic hosts suggests that other species could contain epiphitic X. campestris pv. phaseoli.
\end{abstract}

El papel de las malezas en la supervivencia y dise-minación de varias enfermedades bacterianas ha sido bien documentado (Elango y Lozano, 1981; Jones et al, 1986; Latorre y Jones, 1978; Laub y Stall, 1967; McCarter et al, 1983; McCarter-Zorner et al, 1985). Asimismo, se ha reportado en clima templado cierta

1 Presentado en la XXXV Reunión Anual del PCCMCA, San Pedro Sula, Honduras 1989

2 M.S., División Fitopatología, Depto. Sanidad Vegetal, S.E.A., República Dominicana.

${ }^{3}$ Ph. D., Depto. Fitopatología, Universidad de Nebraska, Lincoln,. U.S.A.

${ }^{4} \mathrm{El}$ abstract y el compendio fueron elaborados por el Comité Edito-rial para mostrar el formato de presentación de los artículos.

Publicado en Agronomía Mesoamericana, Vol. 1 (1990). 
relación entre malezas comunes y $X$. campestris pv. phaseoli (Cafati y Saettler, 1980; Gardner, 1924; Schuster, 1967). Fuertes infestaciones de malas hierbas son problemas frecuentes en las distintas zonas de cultivo de frijol en el mundo, particularmente en los trópicos. Se ha sugerido que las malezas, así como cultivos asociados tales como el maíz, podrían funcionar como importantes fuentes de inóculos del tizón común en regiones productoras de frijol en clima tropical y subtropical (Cafati y Saettler, 1980).

Xanthomonas atípicas pueden ser encontradas en la naturaleza asociadas con las plantas bajo diferentes condiciones. Ciertas Xanthomonas han sido reportadas con actividad saprofíticas en yemas de manzanas (Mass et al, 1985). Otras han sido aisladas de frutos y vegetales con síntomas de podredumbres suaves (Liao y Wells, 1987). Las Xanthomonas pectolíticas pueden ser patógenos oportunistas o sobrevivir epifíticamente sobre plantas cultivadas y malezas. Sin embargo, su posición taxonómica no ha sido definida (Gitaitis et al, 1987).

\section{OBJETIVO}

Este estudio es el primero en examinar poblaciones de X. campestris pv. phaseoli y otras Xanthomonas atípicas, que ocurren en forma, natural en malezas asintomáticas, con el uso de un medio semiselectivo y muestreo de campos de frijol, en la República Dominicana.

\section{MATERIALES Y MÉTODOS}

\section{Muestreos y Aislamientos}

Un total de 77 muestras, incluyendo 21 especies de malezas, fueron colectadas al azar dentro de campos infectados de tizón común y en los alrededores aproximadamente de 2 a $10 \mathrm{~m}$ de los bordes en las localidades de San Juan (Región Suroeste), e Higuey (Región Este) y una semana después de la cosecha en Constanza (Región Norte) en la República Dominicana. En general, tres muestras de hojas fueron tomadas de cada especie de maleza, identificadas y transportadas a Lincoln, $\mathrm{Ne}$ braska, U.S.A.

Los aislamientos fueron realizados añadiendo 10 $\mathrm{ml}$ de bufer $\left(12,5 \mathrm{mM} \mathrm{K}_{2} \mathrm{PO}_{4}+10 \mathrm{mM} \mathrm{Mg} \mathrm{SO}, \mathrm{pH}=\right.$ $7,1)$ a 3-5 hojas en una funda plástica y agitando por 2 horas a 180 RPM. Para cada muestra se prepararon diluciones en serie de 10-1 - 10-3 y las poblaciones de bacterias fueron determinadas esparciendo $0.1 \mathrm{ml}$ de dilución del lavado foliar en la superficie de platos duplicados del medio semiselectivo MXP (Claflin et al, 1987). Después de incubar las placas petri a $26^{\circ} \mathrm{C}$ por 2 3 días, se realizó el conteo de colonias amarillas características con hidrólisis de almidón. La purificación se, realizó transfiriendo 3 veces 2 colonias aislada a medio
YDC (Schaad, 1980) y luego se seleccionaron 132 aislamientos, los cuales fueron conservados en medio YDC o NBY (20) a $4^{\circ} \mathrm{C}$ y también en glicerol estéril al $60 \%$ en bufer, a $-20^{\circ} \mathrm{C}$. Cultivos representativos fueron liofilizados para ser mantenidos por períodos largos.

\section{Pruebas de Patogenicidad}

Plantas de frijol de la variedad "Dark Red Kidney" fueron cultivadas bajo condiciones de invernadero en tarros, cada uno con dos plantas. A los 20 días las hojas fueron inoculadas con 89 aislamientos bacterianos provenientes de malezas colectadas en las localidades de San Juan e Higuey. Hojas trifóliadas de aproximadamente la misma edad en cada planta, fueron inoculadas usando el método de inoculación con puntas de micropipetas (A. Kurnari, comunicación personal). Los síntomas se evaluaron a los 3,7 y 11 días después de la inoculación. Luego se realizó una segunda prueba en hojas de frijol utilizando 13 aislamientos provenientes de la localidad Constanza.

Una tercera prueba fue realizada en legumbres de frijol usando el mismo método de inoculación. 74 aislamientos fueron inoculados en las legumbres de 10 plantas de 79 días edad y la evaluación de los síntomas se hizo de la misma manera que en las pruebas precedentes. A los 21 días después de la inoculación, 24 legumbres de diferentes etapa de desarrollo fueron cosechadas individualmente para evaluar la presencia de bacterias en las semillas. De cada legumbre se tomaron de 3 a 5 semillas en forma aséptica y se colocaron en platos petri con medio NBY. La incubación se realizó a $26^{\circ} \mathrm{C}$ y el crecimiento de bacterias se evaluó hasta un máximo de 6 días.

\section{Características Bioquímicas}

Para confirmar y ampliar la reacción de hidrólis de almidón observada en el medio MXP, aislamientos seleccionados fueron cultivados en el mismo medio modificado con una cantidad doble de metil violeta $2 \mathrm{~B}$ (60 ul/lt, solución al $1 \%$ en Etanol 20\%) y metil verde (120 ul/t; solución acuosa al 1\%). La reacción se observó directamente e inundando los platos con solución de Lugol al 10\%, a los 3 días de incubación.

La producción de pigmento marrón "fuscans" melanina) fue evaluada en aislamientos seleccionados sembrados en platos petri conteniendo medio B de King et al (1954); así como en tubos de ensayos de 7,5 x $0,9 \mathrm{~cm}$ con medio NBY sin glucosa ni $\mathrm{MgSO}_{4}$ (C. Ishimaru, comunicación personal). Ambas pruebas se realizaron por duplicado.

La producción de enzimas pectolíticas por diferentes aislamientos bacterianos fue determinada en un medio de polipectato de sodio y cristal violeta, CVP (Schaad, 1980). 


\section{Cromatografia de Capa Fina del Pigmento Xantho- monadin}

El procedimiento usado fue una modificación del método de Irey y Stall (1981). Se seleccionaron 17 aislamientos, los cuales se cultivaron a $26^{\circ} \mathrm{C}$ en medio B de King et al. A los 2 días las células bacterianas fueron colectadas y suspendidas en $1,5 \mathrm{ml}$ de metanol en tubos plásticos de $2 \mathrm{ml}$ de capacidad, provistos de tapas de rosca. La suspensión se hirvió a $90^{\circ} \mathrm{C}$ por 10 minutos en un módulo calentador Tempb1ok (Curtin Matheson Scientific Inc. U.S.A.), luego se enfrió a temperatura ambiente. Después centrifugar por 10 minutos a 1500 RPM en una centrífuga Eppendorf modelo 5413 (Brinkmann Insemets, Inc. Westbury, New York) para precipitar los desechos de células, el sobre nadante conteniendo la suspensión metanólica fue decantado y evaporado a $75^{\circ} \mathrm{C}$ por $40-50$ minutos hasta aproximadamente $1 \mathrm{ml}$.

Los extractos concentrados amarillos fueron enfriados a temperatura ambiente y luego colocados con una micropipeta de precisión de $100 \mu \mathrm{l}$ (microlitros) usando gotas de $5 \mathrm{ml}$ por muestras, sobre platos de vidrio acanalados para cromatografía de capa fina, cubiertas de gel de sílica 60, con 250 um (micrometros) de grosor y $\mathrm{km}$ preabsorbentes (Wahtman International Ltd. Maidstone, Inglaterra).

Las gotas de los extractos se colocaron en cada canal a $5 \mathrm{~mm}$ debajo de la interface preabsorbente y se secaron completamente antes de la separación con metanol. La cámara se saturó previamente con el solvente. Las separaciones fueron realizadas a temperatura ambiente y los valores Rf se midieron a partir de las interfaces de las áreas preabsorbentes de gel de sílica. Como control se usaron el pigmento xanthomonadin extraído del aislamiento A6-LB 1 de X. campestris pv. phaseoli y el pigmento amarillo del aislamiento C9- IB1 de Erwinia herbicola.

\section{RESULTADOS}

\section{Aislamientos y poblaciones de bacterias}

De un total de 77 muestras de malezas colectadas en las tres localidades, solamente 4 no produjeron algún crecimiento bacteriano en el medio semilectivo MXP. Algunas colonias que crecieron en MXP no hidrolizaron el almidón, mientras otras no crecieron al ser transferidas a medio YDC. Colonias amarillas que hidrolizaban el almidón fueron principalmente seleccionadas para análisis posteriores.

Cuando los aislamientos seleccionados se transferían después de 2 días a $26^{\circ} \mathrm{C}$, para mantenerlos a $4^{\circ} \mathrm{C}$, se observó que los aislamientos que luego fueron identificados como no patogénicos en frijol, continuaban creciendo en medio YDC, mientras que los patogénicos no crecían o tenían un crecimiento poco significativo.

La población promedio de $X$. campestris pv. phaseoli en 14 muestras de 8 especies de malezas osciló enre $10^{3}-10^{5} \mathrm{CFU} / \mathrm{ml}$ del lavado foliar y la población de xanthomonas atípicas varió entre $10_{2}-10_{6} \mathrm{CFU} / \mathrm{ml}$ (Cuadro 1).

\section{Pruebas de Patogenicidad}

Los resultados de las pruebas de patogenicidad, así como otras propiedades de los aislamientos seleccionados se muestran en el Cuadro 2. Al ser inoculadas en hojas de frijol los aislamientos patogénicos provenientes de malezas indujeron una pequeña mancha acuosa alrededor del punto de inoculación a los 3-4 días. A 7 días aproximadamente, se observó un ligero halo amarillento. Este halo se tornó amarillo intenso a los 10- 11 días y rodeaba un centro color marrón pálido. Luego los tejidos alrededor del sitio de inoculación

Cuadro 1. Poblaciones de X. campestris pv. phaseoli y Xanthomomas atípicas en malezas, aisladas en MXP

A. Localidad San Juan de la Maguana

\begin{tabular}{|c|c|c|c|}
\hline \multirow[t]{2}{*}{ Especie de maleza } & \multirow[t]{2}{*}{ Familia } & \multicolumn{2}{|c|}{$\begin{array}{l}\text { Poblaciones }(\mathrm{Log} . \mathrm{CFU} / \mathrm{ml}) \\
X \text {. campestris Xanthomonas }\end{array}$} \\
\hline & & pv. phaseoli & Atípicas \\
\hline Panicum maximun (B) & Gramineae & NB & 4,39 \\
\hline Euphorbia heterophylla (B) & Eupitorbiaceae & NB & 4,91 \\
\hline Euphorbia heterophylla (I) & Euphorbiacm & NB & 4,70 \\
\hline Cleome viscosa $(\mathrm{B})$ & Capparaceae & NB & 6,51 \\
\hline Macroptilium lathyroides & & & \\
\hline (B) & Leguminosae & NB & 4,58 \\
\hline Lagascea mollis (B) & Compositae & NB & 5,47 \\
\hline Lagascea mollis (I) & Compositae & NB & 4,90 \\
\hline Rhynchosia minima (B) & Leguminosae & 4,80 & 5,78 \\
\hline Aeschynomene americana & & & \\
\hline (I) & Leguminosae & 4,56 & 4,38 \\
\hline Cassia tora (I) & Leguminosae & NB & 5,07 \\
\hline Partenium hysterphorus (I) & Compositae & NB & 5,46 \\
\hline
\end{tabular}

B. Localidad: Higuey, R.D.

Acanthospermun hispidum

(I)

Leptochloa filiformis (B)

Leptochloa filiformis (B)

Euphorbia heterophylla (I)

Portulaca oleracea (I)

Echinochloa colonum (I)

Borreira laevis (B)

Eleusine indica (B)

Malachra alceifolia (B)

Malwasmim sp. (B)

Corchorus aestuan (B)

Compositae

Gramineae

Gramineae

Euphorbiaceae

Portulacaceae

Gramineae

Rubiaceae

Gramineae

Malvaceae

Malvaceae

Tiliaceae

5,43

5,20

NB

3,22

3,77

4,45

NB

NB

3,51

NB

NB

3,65

$\mathrm{NE}$

5,00

NB

5,10

NB

3,83

3,71

4,76

4,40

C. Localidad: Constanza R.D.

Portulaca olerace (DC) Portulacaceae NB $\quad 4,06$

Amaranthos sp (DC) Amaranthaceae NB $\quad 4,32$

Setaria sp. (DC) Gramineae NB $\quad$ 2,52

Chenopodiam album (DC) Chenopodiaceae NB NB

Acanthospermun hispidum

(DC)

Compocitae

NB 
Cuadro 2. Comprobación entre algunas propiedades de aislamientos seleccionados de $X$. campestris pv. phaseoli y Xanthomonas atípicas aisladas de malezas.

\begin{tabular}{lccc}
\hline Características & $\begin{array}{c}\text { No. aislamien- } \\
\text { tos probados }\end{array}$ & $\begin{array}{c}X . \\
\text { campestris } \\
\text { pv. phaseoli }\end{array}$ & $\begin{array}{c}\text { Xanthomonas } \\
\text { atípicas }\end{array}$ \\
\hline
\end{tabular}

\begin{tabular}{lccc}
\hline $\begin{array}{l}\text { Colonias amarillas } \\
\text { en YDC y MXP }\end{array}$ & 102 & $+(22) \mathrm{b}$ & $+(80)$ \\
$\begin{array}{l}\text { Hidrólisis de almi- } \\
\text { dón en MXP }\end{array}$ & 102 & $+(22)$ & $+(80)$ \\
$\begin{array}{l}\text { Patogenicidad en } \\
\text { hojas de frijol }\end{array}$ & 102 & $+(22)$ & $-(52)$ \\
$\begin{array}{l}\text { Actividad pecto- } \\
\text { lítica en CUP }\end{array}$ & 38 & $-(16)$ & $+(22)$ \\
$\begin{array}{l}\text { Pigmento "fus- } \\
\text { cans" en NBY } \\
\text { modificado y }\end{array}$ & & & \\
medio B de & & & \\
$\begin{array}{l}\text { King } \text { et al. } \\
\text { Valor Rf de } \\
\text { aprox. } 0,45 \text { a }\end{array}$ & 44 & $-(22)$ & $-(22)$ \\
\hline
\end{tabular}

$+=$ Reacción positiva

- = Reacción negativa

$\mathrm{a}=$ Promedio de 2 platos de gel de sílica

$\mathrm{b}=$ Los números en paréntesis indica No. de aislamientos

se tornaron totalmente necróticos. Alrededor de las 2 semanas, la zona amarilla se había expandido y cubría una área amplia alrededor del centro necrótico marrón.

Los aislamientos no patogénicos provocaron una respuesta incompatible débil en los tejidos de las hojas frijol inoculados.

Las legumbres de frijol inoculadas con aislamientos fitopatogénicos mostraron los síntomas típicos más temprano que las hojas. Alrededor de 3 días después de la inoculación, una mancha acuosa visible rodeaba el sitio de inoculación.

Después de 7 días, la mancha se tornó más grande y adquirió un aspecto acuoso grasiento.

En muchos casos, después de 10 días, la mancha grasienta se diseminó sobre la superficie de la legumbre, dependiendo básicamente de la etapa fisiológica del fruto. Algunas veces se notó un color púrpura alrededor o mezclado con los síntomas de mancha acuosa grasienta.

Los aislamientos no patogénicos inoculados causaron una respuesta incompatible muy fuerte en los tejidos de las legumbres y la intensidad de la reacción aparentemente decrecía con la edad del fruto. A las 24 horas después de la inoculación, los tejidos reaccionaron con una coloración marrón. Alrededor de los 3 días, el área que circundaba el sitio de inoculación, presentaba un color marrón rojizo. Las legumbres más jóvenes mostraron manchas marrones oscuras con apariencia de podredumbre después de 11 días.

Todos los aislamientos patogénicos en las hojas fueron patogénicos en el fruto. En algunos casos se ob- servó exudación bacteriana que salía del punto de inoculación. Siete legumbres con reacción de incompatibilidad presentaron exudado y solo un aislamiento patogénico produjo exudado en la legumbre inoculada.

Las semillas de dos de los nueve frutos seleccionados con reacción incompatible, produjeron crecimiento bacteriano en el medio NBY; mientras que las semillas de los siete frutos seleccionados inoculados con aislamientos patogénicos estaban infectadas externamente. En general, las legumbres verdes y en etapa de maduración tenían más semillas contaminadas con bacterias que las legumbres setas.

En resumen, de 102 aislamientos provenientes de, 77 muestras de 21 especies de malezas, 22 aislamientos (22\%) de 14 muestras de malezas de 8 especies fueron identificadas como $X$. campestris pv. phaseoli por su patogenicidad en hojas y frutos de frijol. La proporción de patogénicos con relación a los no patogénicos fue 1:3.6. La mayoría de los aislamientos patogénicos $(91 \%)$ provenían de malezas coleccionadas dentro de campos infectados. Ninguno de los aislamientos de malezas colectados después de la cosecha en la zona de Constanza causó síntomas en hojas de frijol.

\section{Reacciones Bioquímicas}

La reacción de hidrólisis del almidón en el medio semiselectivo MXP, algunas veces puede ser difícil de distin-guir. Sin embargo, los aislamientos de X. campestris py. phaseoli y de otros Xanthomonas formaron una zona visible bien clara alrededor de las colonias en el centro de las placas petri, después de 3 días, cuando se cultivaron en con una cantidad doble de metil violeta y metil verde. Los aislamientos de $X$. campestris pv. phaseoli provenientes de malezas no crecieron o tuvieron un ctecimiento débil en el medio CVP, sin actividad pectolítica. Por el contrario, las Xanthomonas no patogénicas en frijol, gene-ralmente crecieron bien y mostraron actividad pectolítica positiva después de 48 horas. Las xanthomonas pectolíticas formaron concavidades bien notables sobre la superficie de Agar del medio W. Por otra parte, ninguno de los aisla-mientos bacterianos seleccionados produjo pigmento "fuscans" en el medio B de King el al, ni en el medió NBY modificado.

\section{Producción del Pigmento Xanthomonadin}

Todos los aislamientos incluidos en la prueba, así como el control $X$. campestris pv. phaseoli A6 - LB1, produjeron manchas características de Xanthomonadin con valores $\mathrm{Rf}$ de aproximadamente 0,45 . El pigmento amarillo de E. herbicola C9-1B, tuvo un valor Rf de 0,78.

Los aislamientos provenientes de malezas tuvieron la tendencia de mostrar una segunda mancha en los canales de los platos de gel de sílica. Las manchas de 
xanthomonadin desaparecían a los pocos minutos al secarse los platos de gel de silica.

\section{DISCUSION}

El medio semiselectivo MXP (Claflin et al, 1987) fue una herramienta apropiada para el aislamiento de $X$. campestris pv. phaseoli y Xanthomonas pectolíticas de malezas asintomáticas. Algunas veces, colonias blancas o amarillas sin hidrólisis de almidón crecieron en MXP. Otros aislamientos con colonias amarillas positivas para hidrólisis de almidón, aparentemente, fueron afectadas por algún componente del medio de cultivo, puesto que no pudieron ser resembrados después de 2 meses mantenidos a $4^{\circ} \mathrm{C}$.

Después de la purificación, el uso de una cantidad doble de tinte en MXP fue útil para confirmar y ampliar la evaluación visual de la reacción de hidrólisis de almidón. Una forma de diferencia $X$. campestris pv. phaseoli de los aislamientos no patógenos en frijol, fue la habilidad de estos últimos para seguir creciendo en platos de YDC transferidos de $26{ }^{\circ} \mathrm{C}$ a $4{ }^{\circ} \mathrm{C}$.

La inoculación de colonias bacterianas sin diluir con puntas de micropipetas fue adecuada para la prueba cualitativa de patogenicidad en frijol de aislamientos provenientes de malezas. El desarrollo de los síntomas del tizón común fue típico y se observó un 100\% de correlación entre la patogenicidad en el follaje y las legumbres.

Las xanthomonas pectolíticas no indujeron síntomas de enfermedad en plantas de frijol. La respuesta de incompatibilidad observada en los frutos inoculados parece haber sido una reacción atípica de hipersensibilidad.

Gitaitis et al (1987) encontraron igualmente xanthomonas pectolíticas epifíticas en malezas. La habilidad de estas bacterias para producir enzimas pectolíticas en la superficie foliar se desconoce. Ellas tienen el potencial de causar podredumbre de post cosecha en frutas y vegetales, según lo reportado por Liao y Wells (1987). La inducción de síntomas con apariencia de podredumbre en algunas legumbres jóvenes inoculadas con xanthomonas atípicas podría haber sido causada por la presencia de enzimas pectolíticas.

El medio B de King et al (1954) es usado en forma rutinaria para la detección de Pseudomonas florescentes. Sin embargo, nosotros notamos la producción de un pigmento marrón en ese medio, producido por $X$. campestris pv. phaseoli "fuscans" aislamiento $\mathrm{A}_{1} \mathrm{O}$. La ausencia de pigmento marrón en medio B de King et al. y NBY modificado sugiere que no se aislaron variantes "fuscans" de malezas asintomáticas. Quizás tales variantes se encuentran raramente como epifíticas en malezas comunes en el trópico.

Las colonias de Xanthomonas spp. son difíciles de distinguir de otras bacterias que producen colonias ama- rillas en la mayoría de los medios de cultivo. Irey y Stall (1981) reportaron que xanthomonadin, el pigmento de Xanthomonas spp., tenía un valor Rf de 0,42-0,49 y que otras bacterias amarillas no tenían un pigmento con ese valor Rf. Igualmente, Gitaitis et al (1987) encontraron valores Rf de 0,36-0,49 para xanthomonadin extraído con metanol de xanthomonas pectolíticas amarillas. El valor $\mathrm{Rf}$ promedio de 0,45 encontrado en este estudio para $X$. campestris pv. phaseoli y otras xanthomonas epífiticas concuerda con ambos trabajos de investigación.

Las muestras de malezas colectadas dentro de campos infectados de tizón común, tenían más aislamientos patogénicos de $X$. campestris pv. phaseoli que las muestras que provenían del exterior de los campos o después de la cosecha. Esto sugiere que las malezas asintomáticas contaminadas dentro de campos de frijol, podrían contribuir a la diseminación secundaria de la enfermedad, mientras que las malezas fuera de los campos parecen tener un papel de menor importancia como fuente de inóculo primario.

El hallazgo de 8 especies de malezas pertenecientes a 6 familias botánicas, las cuales pueden actuar como hospederos sin síntomas, indica claramente que otras especies potenciales adicionales podrían, sin duda, ser encontradas albergando $X$. campestris py. phaseoli epifitas, si se realizan más muestreos.

\section{BIBLIOGRAFIA}

CAFATI, C.R.; SAETTLER, A.W. 1980. Role of non-host species as alternate inoculum sources of Xanthomonas phaseoli. Plant Disease 64: 194-196.

; SAETTLER, A.W. 1980. Transmission of Xanthomonas phaseoli in seed of resistant and susceptible phaseolus genotypes. Phytopathology 70: 638-W.

CLAFLIN, L.F.; VIDAVER, A.K., SASSER, M. 1987. MXP, a semiselective medium for Xanthomonas campestris p.v. phaseoli Phytopathology 77:730-734.

ELANGO, F.N.; LOZANO, J.C. 1981. Epiphytic survival of Xanthomonas manihotis on common weeds in Colombia. Proc. Fifth Int. Conf. Plant path. Bact. Cali, Colombia.

ERCOLANI, G.L.; HAGEDORN, D.J.; KELMAN, A.; RAND, R.E 1974. Epiphytic survival of Pseudomonas syringae on hairy vetch in relation to epidemiology of bacteria brown spot of bean in Wisconsin. Phytopathology 64:1330-1339.

GARDNER, M.W. 1924. A native weed host for bacterial blight of bean. Phythology 14:340.

GITAITIS, R.D.; SASSER,MJ.; BEAVER,R.W.; McINNES,T.B.; STALL, R.E. 1987. Pectolytic xanthomonads in mixed infections with Pseudomonas syringae p.v. syringae, $P$. syringae p.v. tomato and Xanthomonas campestris p.v. vesicatoria in tomato and pepper transplants. Phytopathology 77: 611-615.

HIRANO, S.S.; UPPER, C.D. 1983. Ecology and epidemiology of bacterial Plant pathogens. Ann. Rey. Phytopathol. 21:243-269. 
IREY, MS.; STALL, R.E. 1981. Value of Xanthomonadins for identification of pigmented Xanthomonas campestris pathovars. Proc. Fifth Int. COnf. Plant Path. Bact. Cafi, Colombia

JONES, J.B.; POHRONEZNY, K.L.; S . TALL, R.E.; JONES, J.P. 1986. Survival of Xanthomonas campestris p.v. vesicatoria in Florida on tomato crop residue, weeds, seeds and volunteer tomato plants. Phytopathology 76:430-434.

KING,E.O.;WARD,M.K.;RANEY,D.E.1954. Two simple media for the demostration of Pyocyanin and fluorescein. Journal of laboratory and clinical medicirie 44:301-307.

LATORRE, B.A., JONES, A.L. 1978. SurvivaI and pathogenicity to sour cherry of Pseudomonas syringae recovered from weeds and plant refuses. Phytopathology news 12:137 (Resumen).

LAUB, C.A.; STALL, R.E. 1967. An evaluation of Solanum nigrum and Physalis minima as suscepts of Xanthomonas vesicatoria. Plant Dis. Reptr. 51: 659-661.

LEBEN, C. 1995. Epiphytic microorganisms in relation to plant disease. Ann. Rev. Phytopathol. 3: 209-230.

LIAO, C.H.; WELL, J.M. 1987. Association of Pectolytic strains of Xanthomonas campestris with soft rots of fruits and vegetables at retail markets. Phytopathology 77: 418-422.

MASS, J.L.; FINNEY, M.M.; CIVEROLO, E.L.; SASSER, M. 1985. Association of an unusual strain of Xanthomonas campestris with apple. Phytopathology 75: 438-455.
MCCARTER, S.M.; JONES, J.B.; GITAITIS, R.D.; SMITLEY, D.R 1983. Survival of Pseudomonas syringae p.v. tomato in association with tomato seed, soil, host tissue and epiphytic weed host, in Georgia. Phytopathology 73: 1393-1398.

McCARTER-ZORNER, N.J.; HARRISON, M.D.; FRANC, G.D.; QUINN, C.E.; SELLS, I.A.; GRAHAM, D.C. 1985. Soft rot Erwinia bacteria in the rhizosphere of weeds and crop plants in Colorado, United States and Scotland. J. appl. Bacteriol. 59$357-368$

MORRIS, C.E.; ROUSE, D.J. 1982. Diversity of epiphytic bacterial communities on bean (Phaseolus vulgaris) leaves and pods based on nutrient utilization. Phytopathology 72:936 (resumen).

SCHAAD, N. (ed). 1980. Laboratory guide for identification of plant pathogenic bacteria. APS, St. Paul, Mn. 70 pp.

SCHUSTER, M.L. 1967. Survival of bean bacterial pathogensin the field and greenhouse under different environmental conditions. Phytopathology 57: 830 (resumen).

; COYNE, D.P. 1974. Survival mechanisms of Phytophatology bacteria. Ann. Rev. Phytopathol. 12: 199-221.

WELLER, D.M.; SAETTLER, A.W. 1980. Colonization and distribution of Xanthomonas phaseoli and Xanthomonas phaseoli var. fuscans. Phytopathology 70: 500-506.

1980. Evaluation of seedborne Xanthomonas phaseoli and Xanthomonas phaseoli var fuuscans as primary inocula in bean blights. Phytopathology 70: 148-152. 